\title{
TEleHEAlTH: A RAPidly DeVEloping SERVICE DELIVERY MODEL FOR OCCUPATIONAL THERAPY
}

\author{
JANA CASON, DHS, OTR/L, FAOTA \\ AUERBACH SCHOOL OF OCCUPATIONAL THERAPY, SPALDING UNIVERSITY, LOUISVILLE, KENTUCKY, USA
}

\section{ABSTRACT}

Over the past decade, the practice of occupational therapy has been increasingly influenced by technological advances in the use of information and communication technologies (ICT) and associated changes in health care policy. Emergent from this evolution is the application of telehealth to deliver occupational therapy services to a client who is in a different physical location than the provider. This article furnishes an overview of the evidence for telehealth use in occupational therapy, discusses key policy considerations, and provides resources to guide practitioners in the ethical use of telehealth.

Keywords: Licensure portability, occupational therapy, telehealth, telerehabilitation

Over the past decade, the practice of occupational therapy (OT) has been increasingly influenced by technological advances in the use of information and communication technologies (ICT) and associated changes in health care policy. Emergent from this evolution is the application of telehealth to deliver OT services to clients who are in a different physical location than the provider. AOTA (2013b) defines telehealth as "the application of evaluative, consultative, preventative, and therapeutic services delivered through telecommunication and information technologies" (p. S69). While telehealth may include both synchronous (live) and asynchronous (store and forward) technologies, synchronous applications in the form of videoconferencing are cited most often in the literature in reference to services provided by rehabilitation professionals.

This article furnishes an overview of the developing evidence for telehealth use in occupational therapy, discusses key policy considerations, and provides resources to guide practitioners in the ethical use of telehealth.

\section{TELEHEALTH EFFICACY}

It is increasingly evident that telehealth can improve access to rehabilitation services and specialists; prevent unnecessary delays in receiving care, including weather events impacting travel (Cason \& Cohn, 2014); and facilitate coordinated care and interprofessional collaboration (Cason, 2012). The World Health Organization (WHO) affirms the efficacy of telehealth as an effective service delivery model for rehabilitation professionals (i.e., telerehabilitation). The
WHO and World Bank (2010), in their co-produced World Report on Disability, reviewed research on the use of telehealth to provide services for mental health, cardiac rehabilitation, remote assessment for home modifications, consultation for prosthetics, orthotics, and wheelchair prescription, and cognitive rehabilitation among other services and concluded: "Growing evidence on the efficacy and effectiveness of telerehabilitation shows that telerehabilitation leads to similar or better clinical outcomes when compared with conventional interventions (p. 119)."

Research supports the use of telehealth as a service delivery model in occupational therapy (Kairy, Lehoux, Vincent, \& Visintin, 2009; Steel, Cox, \& Garry, 2011). The AOTA (2013b) Telehealth position paper cites compelling research in the areas of wheelchair prescription, neurological assessment, adaptive equipment prescription and home modification, ergonomic assessment, school-based practice, early intervention services, health and wellness programming, and rehabilitation for individuals who have experienced stroke, breast cancer, traumatic brain injury, polytrauma, Parkinson's disease, and other neurological and orthopedic impairments.

Several comparative efficacy studies also conclude that there is no significant difference in clinical outcomes between occupational therapy services provided in-person and services provided through telehealth for wheelchair assessment (Barlow, Liu, \& Sekulic, 2009; Schein et al, 2011), pre-admission orthopedic occupational therapy home visits (Hoffmann \& Russell, 2008), assessment of activities of daily living and hand function in individuals with Parkinson's disease (Hoffmann, Russell, Thompson, Vincent, \& Nelson, 2008), and ergonomic assessment (Jacobs, Blanchard, \& Baker, 
2012). Additionally, high satisfaction among service recipients is reported.

Studies suggest that with some populations and interventions, telehealth may result in better outcomes than in-person services (Kinley et al., 2012; TaberDoughty, Shurr, Brewer, \& Kubik, 2010). In their review of telehealth literature for mental health and substance abuse, Kinley et al. (2012) identified smoking cessation as one area where telehealth yielded better outcomes than alternative (e.g., in-person) approaches. Using a single case study with alternating treatment design with baseline and follow-up conditions, Taber-Doughty, Shurr, Brewer, and Kubik (2010) compared the level of independence of adults with intellectual disabilities living in integrated community settings following standard care and telecare (i.e., telehealth). The use of telehealth resulted in participants completing novel household activities with greater independence than the in-person treatment condition; however, the researchers cautioned against overgeneralization of the results.

Interventions that require physical handling and/or interpretation of subtle body or contextual cues may not be as effective when delivered through telehealth technologies (Jacobs, Blanchard, \& Baker, 2012). However, even 'hands on' interventions (e.g., Neuro Developmental Treatment or NDT) can be supported through telehealth by using a consultative approach between an expert and novice practitioner (Forducey et al., 2003).

Current telehealth evidence is encouraging, though limited. Further research is needed to determine which OT assessments and interventions are amenable to a telehealth service delivery model.

\section{TELEHEAlTh: A SERVICE DELIVERY MODEL}

It is important to recognize that telehealth is a service delivery model that is used to deliver a service such as OT. Telehealth is not a distinct and separate intervention. Therefore, the use of telehealth is within the purview of existing occupational therapy scopes of practice.

All requirements to adhere to state, federal, and ethical guidelines for OT service delivery are the same whether services are provided in-person or through telehealth technologies (AOTA, 2013a; 2013b). While many licensure boards have adopted AOTA's position on the use of telehealth, telehealth regulations and policies often differ between states. It is therefore incumbent upon a practitioner to determine if there are prescriptive telehealth laws, regulations, or policies in the state wherein the practitioner is located at the time of service, and (if different) the state wherein the client is located at the time of service (AOTA, 2013b; Cason \& Brannon, 2011).
Technologies and software employed for delivery of OT services via telehealth must meet the Health Insurance Portability and Accountability Act (HIPAA; Pub.L. 104-191, 110 Stat. 1936) and the Health Information Technology for Economic and Clinical Health Act (HITECH) requirements for privacy, security, and confidentiality of protected health information (PHI). Risk analysis resources, including a checklist to analyze commercial videoconferencing software (Watzlaf, Moeini, \& Firouzan, 2010) can inform practitioners' compliance with HIPAA and HITECH requirements for privacy, security, and confidentiality of $\mathrm{PHI}$.

\section{TELEHEAlth ReIMBURSEMENT}

Despite AOTA's (2013b) assertion that "OT services provided with telehealth technologies should be valued, recognized, and reimbursed the same as services provided in person (p. S75)," reimbursement for telehealth, while promising, is not yet universal.

Positive trends toward reimbursement include the following. Telehealth reimbursement is expanding with legislative mandates for coverage by private insurance in 22 states at the time of this writing (American Telemedicine Association; ATA, 2014b). In some cases, contractual arrangements and private pay are sources of reimbursement for OT services provided via telehealth. The Department of Defense (U.S. Department of Defense, 2014) and Veterans Health Administration (U.S. Department of Veterans Affairs, 2014a) have significantly expanded their programming and financial support for telehealth. The Patient Protection and Affordable Care Act (2010; Public Law 111-148) created opportunities for inclusion of telehealth in innovative service delivery and payment models; however, education and advocacy is needed for full inclusion of OT in these novel coordinated care and service delivery models (Cason, 2012).

Despite these advances, telehealth reimbursement is not universal. The Center for Medicare and Medicaid Services (CMS) Telehealth Provider List (CMS, 2012) does not include OT practitioners (nor other rehabilitation providers) as reimbursed 'telehealth providers' for Medicare beneficiaries. Medicaid reimbursement still varies by state (ATA, 2014a). For example, Kentucky and New Mexico's Medicaid programs currently reimburse OT, physical therapy (PT), and speech-language pathology (SLP) services delivered via telehealth. In contrast, Virginia and Ohio have provisions for SLP services delivered via telehealth services, but not for telehealth delivered OT or PT services (ATA, 2014a). AOTA is working in concert with practitioners and stakeholders to advocate for expanded reimbursement of OT services provided via telehealth. 


\section{INTERSTATE PRACTICE AND TELEHEALTH}

With the exception of clinical practice within the federal health care system, practitioners must hold a professional license in the state wherein the client is located. The benefits of telehealth cannot be fully realized unless providers can practice across state lines with greater ease, perhaps via interstate license portability or another approach that can facilitate improved access.

There are many potential benefits of interstate license portability. Clients, regardless of geographic location, would enjoy greater ease of access to specialists. State governments could reduce duplicative processes and administrative costs, perhaps redistributing resources to bolster consumer protection. Practitioners might experience less delays, expense and effort associated with obtaining, maintaining, and renewing multiple state licenses (Brannon, Cohn, \& Cason, 2012; Cohn, Brannon, \& Cason, 2011; Cason \& Brannon, 2011).

The research that follows provides exemplars of how interstate practice benefits clients with complex medical conditions that require specialized clinical management.

\section{INTERSTATE PRACTICE FOR CHILDREN WITH COMPLEX FEEDING DISORDERS}

Children and families participating in the Feeding Program at Children's Hospital in Richmond, Virginia travel significant distances to receive intensive feedingrelated services. Families remain at the hospital for weeks at a time while their children receive care from an interprofessional team of feeding specialists in the day patient or outpatient feeding program (Children's Hospital of Richmond at Virginia Commonwealth University, 2014). A pilot telehealth program enabled specialists from the Children's Hospital to connect with children, families, and local health care providers within the children's communities (Clawson et al., 2008). Participants $(n=15)$ resided in 11 states and one foreign country. Half of the children were effectively treated in their local communities via telehealth technologies; the other half required more intensive care via admission to the Children's Hospital day patient treatment program. Participants who were able to remain in their local communities experienced cost savings, as well as less significant disruptions of caregivers' work and family routines and other occupational roles. Positive clinical outcomes (e.g., reduced reliance on feeding tubes) occurred. Both parents and local providers expressed a high level of satisfaction with telehealth use. The local health care providers reported improved skill and confidence as a result of consultation with the specialists.

This study provides evidence that telehealth use across state lines can yield high family and provider satisfaction, cost savings, and positive clinical outcomes for children with complex feeding disorders.
INTERSTATE PRACTICE FOR CLIENTS WITH PROSTHETIC DEVICES

Whelan and Wagner (2011) point to the lack of licensure portability as a significant barrier to caring for clients with upper limb amputations fitted for prosthetic devices. Clients (i.e., users of prosthetics) receive intensive prosthetic fitting and training services at the prosthetic company headquarters; many require technical and clinical support when they return home and attempt to resume their daily routines (Whelan \& Wagner, 2011). Due to the low incidence of upper limb amputation, there is a shortage of community-based prosthetic rehabilitation experts who can fully support these clients' integration of the prosthetic devices into their activities of daily living (ADLs) and instrumental activities of daily living (IADLs). While the specialized OTs employed by the prosthetic company may provide technical support at a distance (i.e., remote adjustment of the prosthetic device using Bluetooth-enabled technologies), cumbersome state licensure requirements too often inhibit their capacity to provide clinical support (Whelan \& Wagner, 2011).

\section{INTERSTATE PRACTICE IN THE VA AND DOD HEALTHCARE SYSTEMS}

OTs are involved in many and diverse telehealth programs that support rehabilitation and health and wellness services within the U.S. Department of Veterans Affairs (VA) healthcare system (U.S. Department of Veterans Affairs, 2014a). Current telehealth programming includes: Polytrauma, TeleAmputation clinics, TeleCardiology, TeleGenomics, TelelCU, TeleMental Health, TeleMOVE! (an innovative health and wellness program), TeleNeurology, TeleNutrition, TeleOccupational Therapy, TelePrimary Care, TelePulmonology (sleep services), TeleRehabilitation, TeleSurgery (consultation, education, and pre-/post-operative assessment), and TeleSpinal Cord Injury/Disorder (U.S. Department of Veterans Affairs, 2014b). A growing body of evidence demonstrates positive outcomes associated with the VA's use of telehealth to support health related service delivery for veterans (Bendixen, Levy, Olive, Kobb \& Mann, 2009; Darkins, Cruise, Armstrong, Peters, \& Finn, 2008; Sanford et al., 2007).

Informing the discussion of interstate practice is the Department of Defense (DOD) and Veterans Affairs licensing/credentialing model. OT practitioners credentialed through the DOD and VA and licensed in one state can provide services across state lines provided the service recipient is located on federal property (i.e., military installations, VA hospitals, etc.). Recent federal legislation has further expanded licensure portability. In 2011, the Servicemembers' Telemedicine and E-Health Portability Act (STEP Act) was signed into law as part of the National Defense Authorization Act (NDAA) for Fiscal 
Year 2012. The STEP Act expanded licensure exemption provisions for DOD clinicians, licensed civilians, and contractors (Thompson, 2011).

\section{LICENSURE PORTABILITY}

Over a decade ago, the Health Licensing Board Report to Congress (U.S. Department of Health and Human Services, 2001) persuasively articulated the value of licensure portability to improve access to health care services, facilitate workforce mobility, and overcome shortages of healthcare professionals. Many licensure portability models now exist, including mutual recognition compacts, expedited license, limited license, national license, and federal pre-emption (Cohn, Brannon, \& Cason, 2011).

In 2014, national efforts and grass root initiatives increasingly support state licensure portability (ATA, 2012a, 2013a). The National Association of State EMS Officials, Federation of State Medical Boards, Federation of State Boards of Physical Therapy, and the Association of State and Provincial Psychology Boards are each exploring the mutual recognition/compact model as a means to facilitate licensure portability within their respective professions (deGolian, 2014; FSBPT, 2011; FSMB, 2013). While efforts to overcome barriers to licensure portability are underway, these are often single-discipline in scope. A notable exception is the interprofessional workgroup convened by the American Telemedicine Association's Telerehabilitation Special Interest Group (TR SIG), which discussed licensure portability for rehabilitation professionals (Brannon, Cohn, \& Cason, 2012; Cohn, Brannon, \& Cason, 2011).

\section{IMPORTANT TELEHEALTH POLICY CONSIDERATIONS}

As professional state regulatory boards respond to telehealth inquiries and engage in discussions around telehealth policy, their commission to uphold the welfare of consumers is of utmost concern. Such discussions can be informed by the evidence generated by research and the telehealth expertise that continues to grow across many professions.

State telehealth policies should not become unduly prescriptive, because technologies are rapidly evolving, consumers are becoming more accustomed to and even expectant of Web-based services, and clients' circumstances vary. Instead, the judgments of competent, ethical practitioners should reign paramount; expert clinical reasoning can best guide the use of telehealth. The previously cited examples of children with complex feeding disorders and individuals with high-tech prosthetic devices demonstrate why an appropriately licensed professional need not be physically located near the client.

Similarly, the arbitrary requirement that a client must first be seen in-person by the practitioner before receiving services via telehealth is not universally appropriate; this is best determined by a practitioner's clinical reasoning and ethical judgment. Evidence demonstrates that clients can be effectively treated without first being seen inperson by the remote practitioner (AOTA, 2013b; Clawson et al., 2008; Jacobs, Blanchard, \& Baker, 2012).

Well-meaning telehealth regulations that create barriers and limit telehealth provision can inadvertently 'harm the consumer' by denying access to OT services and specialists who might otherwise be unavailable within the local community.

\section{TELEHEALTH RESOURCES TO GUIDE PRACTICE}

\section{AMERICAN OCCUPATIONAL THERAPY ASSOCIATION}

In anticipation of the important role telehealth will play in the delivery of health care services, the American Occupational Therapy Association (AOTA) continues to update and expand telehealth resources for OT practitioners. These include the Telehealth Position Paper (AOTA, 2013b) and Telehealth Ethics Advisory Opinion (AOTA, 2013a). AOTA also published a telehealth-related Continuing Education (CE) article (Cason, 2012a) and Pediatric Virtual Chat (Cason, Hartmann, \& Crutchley, 2011); a telehealth policy article in the American Journal of Occupational Therapy (Cason, 2012b); a discussion forum dedicated to telehealth/telerehabilitation on OT Connections (Technology Special Interest Section); AOTA-sponsored telehealth presentations at the AOTA annual conferences; and numerous resources available on AOTA's website, many linked to the Emerging Niche: Telehealth web page (AOTA, 2014). OT practitioners can gain telehealth knowledge and skills via a variety of resources, continuing education opportunities (i.e., conference, webinars, CE article, etc.), and mentoring relationships.

OT students are also acquiring the knowledge and skills to facilitate their use of telehealth upon graduation from accredited OT programs. The Accreditation Council for Occupational Therapy Education (ACOTE, 2013) now requires students to:

demonstrate an understanding of the use of technology to support performance, participation, and health and well-being. This technology may include, but is not limited to, electronic documentation systems, distance communication, virtual environments, and telehealth technology. (ACOTE Standard B.1.8) 
OT training programs across the country are thus beginning to integrate telehealth into entry-level and post-professional OT curriculum.

\section{AMERICAN TELEMEDICINE ASSOCIATION}

The American Telemedicine Association (ATA) is a leading international telehealth advocacy organization and seeks to educate and engage stakeholders; advance telehealth policy; foster networking, collaboration, and research; and develop and disseminate telehealth standards and guidelines (ATA, 2012). The American Telemedicine Association's Telerehabilitation Special Interest Group (TR SIG) produced the oft cited document, A Blueprint for Telerehabilitation Guidelines, a key resource providing guidance on administrative, clinical, technical, and ethical considerations associated with the use of telehealth/telerehabilitation (ATA, 2010). Occupational therapy practitioners can access this and other telehealth resources on ATA's website.

\section{Telehealth Resource CENTERS/ NETWORKS}

Practitioners interested in integrating telehealth into their existing OT practice may benefit from national and regional telehealth resource centers (Telehealth Resource Centers, 2013). Funded by the Office for the Advancement of Telehealth (OAT), these centers provide telehealth program development resources including online modules on telehealth operations, reimbursement, legal and regulatory considerations, marketing, and practitioner training (Telehealth Resource Centers, 2013).

\section{CONCLUSION}

Telehealth service delivery is a rapidly growing force in the healthcare environment. There is increasing evidence that many OT services are amenable to a telehealth service delivery model. Telehealth can improve access to occupational therapy services and specialists; prevent unnecessary delays in receiving care; and facilitate coordinated care and interprofessional collaboration. This is therefore a propitious time to craft 'least restrictive' telehealth policies that underscore the value of evidencebased practice and competent clinical judgment. 
REFERENCES

1. Accreditation Council for Occupational Therapy Education [ACOTE]. (2013). 2011 Accreditation Standards and Interpretive Guide (Effective July 31, 2013) December 2013 Interpretive Guide version. Retrieved from http://www.aota.org/-/media/Corporate/Files/ EducationCareers/Accredit/Draft-Standards/2011Standards-and-Interpretive-Guide-August-2013.pdf

2. American Occupational Therapy Association. (2014). Emerging niche: Telehealth. Retrieved from http://www. aota.org/Practice/Rehabilitation-Disability/EmergingNiche/Telehealth.aspx

3. American Occupational Therapy Association. (2013a). Telehealth ethics advisory opinion. Retrieved from http:// www.aota.org//media/Corporate/Files/Practice/Ethics/ Advisory/telehealth-advisory.pdf

4. American Occupational Therapy Association. (2013b). Telehealth [Position paper]. American Journal of Occupational Therapy, 67(Suppl), S69-S90. doi:10.5014/ ajot.2013.67S69

5. American Telemedicine Association. (2014a). State Medicaid best practice-Telerehabilitation (January 2014). Retrieved from http://www.americantelemed.org/docs/ default-source/policy/state-medicaid-best-practice--telerehabilitation.pdf?sfvrsn $=4$

6. American Telemedicine Association. (2014b). 2014 State Telemedicine Legislation Tracking (as of 6/24/2014). Retrieved from http://www.americantelemed.org/docs/ default-source/policy/state-telemedicine-policy-matrix. pdf?sfvrsn $=32$

7. American Telemedicine Association. (2013). Removing medical licensure barriers: Increasing consumer choice, improving safety and cutting costs for patients across America. Retrieved from http://www.americantelemed. org/fixlicensure-org

8. American Telemedicine Association. (2012). ATA applauds congressional proposal to increase telemedicine reimbursement, fix licensure for federal health programs. Retrieved from http://www.americantelemed.org/ news-landing/2013/01/04/ata-applauds-congressionalproposal-to-increase-telemedicine-reimbursement-fixlicensure-for-federal-health-programs

9. American Telemedicine Association. (2010). A blueprint for telerehabilitation guidelines. Retrieved from http://www. americantelemed.org/docs/default-source/standards/ablueprint-for-telerehabilitation-guidelines.pdf?sfvrsn=4

10. Barlow, I.G, Liu, L, \& Sekulic, A. (2009). Wheelchair seating assessment and intervention: A comparison between telerehabilitation and face-to-face service. International Journal of Telerehabilitation, 1(1), 17-28. doi: 10.5195/ ijt.2009.868. Retrieved from http://telerehab.pitt.edu/ojs/ index.php/Telerehab/article/view/868

11. Bendixen, R., Levy, C., Olive, E., Kobb, R., \& Mann, W. (2009). Cost effectiveness of a telerehabilitation program to support chronically ill and disabled elders in their homes. Telemedicine and eHealth, 15(1), 31-38. doi:10.1089/tmj.2008.0046

12. Brannon, J.A., Cohn, E.R, \& Cason, J. (2012). Making the case for uniformity in professional state licensure requirements. International Journal of Telerehabilitation, 4(1), 41-46. Retrieved from http://telerehab.pitt.edu/ojs/ index.php/Telerehab/article/view/6091

13. Cason, J. (2012a). An introduction to telehealth as a service delivery model within occupational therapy. OT
Practice, 17(4), CE-1-CE-8.

14. Cason, J. (2012b). Telehealth opportunities in occupational therapy through the Affordable Care Act. American Journal of Occupational Therapy, 66, 131-136.

15. Cason, J. \& Brannon, J.A. (2011). Telehealth regulatory and legal considerations: Frequently asked questions. International Journal of Telerehabilitation, 3(2), 15-18. doi: 10.5195/ijt.2011.6077. Retrieved from http://telerehab.pitt. edu/ojs/index.php/Telerehab/article/view/6077

16. Cason, J., \& Cohn, E.R. (2014). Telepractice: An overview and best practices. ASHA Perpectives, 23(1), 4-17.

17. Cason, J., Hartmann, K., \& Crutchley, S. (2011, August 29). Use of telehealth in early intervention and school system practice. American Occupational Therapy Association National Pediatric Virtual Chat. Retrieved from http:// otconnections.aota.org/media/p/78416.aspx

18. Centers for Medicare and Medicaid Services. (2012). Telehealth services. Retrieved from https://www.cms.gov/ Outreach-and-Education/Medicare-Learning-NetworkMLN/MLNProducts/downloads/TelehealthSrvcsfctsht. pdf

19. Children's Hospital of Richmondat Virginia Commonwealth University. (2014). Feeding program. Retrieved from http:// www.chrichmond.org/Services/Feeding-Program.htm

20. Clawson, B., Selden, M., Lacks, M., Deaton, A., Hall, B., \& Bach, R. (2008). Complex pediatric feeding disorders: Using teleconferencing technology to improve access to a treatment program. Pediatric Nursing, 34, 213-216.

21. Cohn, E.R., Brannon, J.A., \& Cason, J. (2011) Resolving barriers to licensure portability for telerehabilitation professionals. International Journal of Telerehabilitation, 3(2), 31-34. doi: 10.5195/ijt.2011.6078. Available at: http://telerehab.pitt.edu/ojs/index.php/Telerehab/article/ view/6078

22. Darkins, A., Cruise, C, Armstrong, M., Peters, J., \& Finn, M. (2008). Enhancing access of combat wounded veterans to specialist rehabilitation services: The VA Polytrauma Telehealth Network. Archives of Physical Medicine and Rehabilitation, 89, 182-187. doi: 10.1016/j. apmr.2007.07.027

23. deGolian, C. (2014, January/February). Medical licensing compacts - A new approach to healthcare. Retrieved from http://www.csg.org/pubs/capitolideas/enews/ issue128_2.aspx

24. Federation of State Boards of Physical Therapy [FSBPT]. (2011). Feasibility of establishing a multistate compact for physical therapy licensure: Report to the delegate assembly on 2010 delegate assembly motion DEL-10-05. Retrieved from http://www.fsbpt.org/download/2011DH_ MultistateCompactReport.pdf

25. Federation of State Medical Boards [FSMB]. (2013). Interstate compact for physician licensure moves forward with consensus principles. Retrieved from http://www. fsmb.org/pdf/nr_interstate_compact.pdf

26. Forducey, P.G., Ruwe, W., Dawson, S.J., ScheidemanMiller, C., McDonal, N.B., \& Hantla, M.R. (2003). Using telerehabilitation to promote $\mathrm{TBI}$ recovery and transfer of knowledge. NeuroRehabilitation, 18, 103-111.

27. Hoffmann, T., \& Russell, T. (2008). Pre-admission orthopaedic occupational therapy home visits conducted using the internet. Journal of Telemedicine and Telecare, 14, 83-87.

28. Hoffmann, T., Russell, T., Thompson, L., Vincent, A., \& Nelson, M. (2008). Using the internet to assess activities of daily living and hand function in people with Parkinson's 
disease. NeuroRehabilitation, 23, 253-261.

29. Jacobs, K., Blanchard, B., \& Baker, N. (2012). Telehealth and ergonomics: A pilot study. Technology and Health Care, 20, 445-458.

30. Kairy, D., Lehoux, P., Vincent, C., \& Visintin, M. (2009). A systematic review of clinical outcomes, clinical process, healthcare utilization and costs associated with telerehabilitation. Disability and Rehabilitation, 31, 427447.

31. Kinley, A., Zibrik, L., Cordeiro, J., Lauscher, H., \& Ho, K. (2012). Telehealth for mental health and substance use: Literature review. BC Ministry of Health, Mental Health, and Substance Use (MUSU) Branch. Retrieved from http://ehealth.med.ubc.ca/files/2013/04/TeleMentalHealth-Literature-Review-FINAL.pdf

32. Schein, R.M., Schmeler, M.R., Holm, M.B., Pramuka, M., Saptono, A., \& Brienza, D.M. (2011). Telerehabilitation assessment using the Functioning Everyday with a Wheelchair-Capacity instrument. Journal of Rehabilitation Research \& Development, 48, 115-124..

33. Sanford, J., Hoenig, H., Griffiths, P., Butterfield, T., Richardson, P., \& Hargraves, K. (2007). A comparison of televideo and traditional in-home rehabilitation in mobility impaired older adults. Physical and Occupational Therapy in Geriatrics, 25(3), 1-18.

34. Steel, K., Cox, D., \& Garry, H. (2011). Therapeutic videoconferencing interventions for the treatment of long-term conditions. Journal of Telemedicine \& Telecare, 17, 109-117.

35. Taber-Doughty, T., Shurr, J., Brewer, J., \& Kubik, S. (2010). Standard care and telecare services: Comparing the effectiveness of two service systems with consumers with intellectual disabilities. Journal of Intellectual Disabilities Research, 54, 843-859.

36. Telehealth Resource Centers. (2013). Telehealth resource centers. Retrieved from http://www. telehealthresourcecenter.org/ Thompson, G. (2011, December 11). Thompson bill included in final national defense policy agreement, provisions praised by army leadership. Retrieved from http://thompson.house.gov/ press-release/thompson-bill-included-final-nationaldefense-policy-agreement-provisions-praised-army

37. U.S. Department of Defense. (2014). National Center for Telehealth \& Technology. Retrieved from http://www. t2.health.mil/

38. U.S. Department of Health and Human Services, Health Resources and Services Administration (2001). Health Licensing Board Report to Congress. Retrieved from http://www.hrsa.gov/ruralhealth/about/telehealth/ licenserpt10.pdf

39. U.S. Department of Veterans Affairs. (2014a). VA telehealth services. Retrieved from http://www.telehealth.va.gov/

40. U.S. Department of Veterans Affairs. (2014b). VA telehealth services: Real-time clinic based video telehealth. Retrieved from http://www.telehealth.va.gov/real-time/ index.asp

41. Watzlaf, V., Fahima, R., Moeini, S., Matusow, L. \& Firouzan, P. (2011). VolP for telerehabilitation: A risk analysis for privacy, security, and HIPAA compliance - Part II. International Journal of Telerehabilitation, 3(1), 3-10. doi: 10.5195/IJT.2011.6070 Available at http://telerehab.pitt.
edu/ojs/index.php/Telerehab/article/view/6070

42. Watzlaf, V., Moeini, S., \& Firouzan, P. (2010). VolP for telerehabilitation: A risk analysis for privacy, security, and HIPAA compliance - Part 1. International Journal of Telerehabilitation, 2(2), 3-14. doi: 10.5195/ijt.2010.6056 Retrieved from http://telerehab.pitt.edu/ojs/index.php/ Telerehab/article/view/6056

43. Whelan, L., \& Wagner, N. (2011). Technology that touches lives: Teleconsultation to benefit persons with upper limb loss. International Journal of Telerehabilitation, 3(2), 19-22. doi: 10.5195/ijt.2011.6080. Retrieved from http://telerehab.pitt.edu/ojs/index.php/Telerehab/article/ view/6080 
